\title{
eLearning in Tourism and Hospitality: A Map
}

Lorenzo Cantoni, NewMinE Lab \& Webatelier.net

Università della Svizzera italiana (University of Lugano)

lorenzo.cantoni@usi.ch

tel. + 41(0)58666 47 20, fax. + 41(0)586664647

via G.Buffi 13, CH-6904 Lugano (Switzerland)

Lorenzo Cantoni holds a $\mathrm{PhD}$ in Education and Linguistics. L. Cantoni is full professor at the University of Lugano (Switzerland), Faculty of Communication Sciences. He is vice-director of the Institute of Public and Educational Communication and vice-Dean. $\mathrm{He}$ is director of the laboratories webatelier.net: production and promotion over the Internet, and NewMinE Lab: New Media in Education Lab.

Nadzeya Kalbaska, webatelier.net

Università della Svizzera italiana (University of Lugano)

nadzeya.kalbaska@usi.ch

tel. $+41(0) 586664788$, fax. + 41(0)58 6664647

via G.Buffi 13, CH-6904 Lugano (Switzerland) 
Nadzeya Kalbaska is finishing her Master in Tourism Management from Università della Svizzera italiana, writing her thesis on Benchmarking of online-training courses in hospitality and tourism field, while collaborating with webatelier.net on projects of eLearning and Tourism.

Alessandro Inversini, webatelier.net

Università della Svizzera italiana, (University of Lugano)

alessandro.inversini@usi.ch

tel. $+41(0) 586664788$, fax. $+41(0) 586664647$

via G.Buffi 13, CH-6904 Lugano (Switzerland)

Alessandro Inversini holds a Master in Communication Sciences and Communication Technologies; he works as researcher at webatelier.net (www.webatelier.net), at the Faculty of Communication Sciences (University of Lugano - www.usi.ch). His research activity primarily deals with usability, quality and new technologies of communication in cultural tourism. He is completing a $\mathrm{PhD}$ research about online communication in the field of cultural tourism. 


\section{eLearning in Tourism and Hospitality: A Map}

\section{Abstract}

The impact of information and communication technologies (ICT) on tourism and hospitality industries has been widely recognized and investigated as a one of the major changes within the domains in the last decade: new ways of communicating with prospective tourists and new ways of purchasing products arisen are now part of the industries' everyday life. Poor attention has been paid so far to the role played by new media in education in these fields. There is a huge and growing interest in the practice of eLearning in different sectors of the industry. This research investigates the role of new media in education in the field of tourism and hospitality, harvesting online courses and categorizing them according to subdomains in order to provide a clear overview of the field. Results may be considered as a first picture of the eLearning domain related to tourism.

\section{keywords}

eLearning, eTourism, tourism training, tourism and hospitality online courses 


\section{Introduction}

According to the European Union, eLearning can be defined as "the use of new multimedia technologies and the Internet to improve the quality of learning by facilitating access to resources and services as well as remote exchanges and collaboration" (CEC 2001, p.1). Depending on the viewpoint of the researcher, it can encompass (i) internet (online) education and training; (ii) the use of Information and Communication Technologies (ICT) in education and training; and (iii) the capacity to transform education and training through the use of ICT (Cantoni \& Tardini, 2006; Cantoni, Botturi, Succi \& New MinE Lab, 2007). In fact, all those perspectives can be applied in the field of tourism, a field in which ICT and the internet have had a paramount impact at all levels, and where acquiring new knowledge and skills is of the utmost importance for all players, clients not excluded.

The hospitality and tourism industry is then a very relevant area where to study the role of eLearning, its penetration, usages, and future perspectives, not to mention success criteria and best practices (as well as problems and failures).

This research presents a tentative map of the eLearning offers within the tourism industry and a research agenda for further investigations is proposed. The paper is structured as follows: after a literature review, which shows interest in the subject by (e-)Tourism researchers, but a substantial lack of research in the eLearning community (Cantoni \& Rega, 2003), a tentative map of the area is offered, based on a multiple case study research design. In this research, only the most restrictive 
meaning of eLearning has been taken into consideration, i.e.: online learning, as it can happen through courses/training modules.

Based onto a sample of 300 cases, the map has been divided into four categories, each of them has been further investigated, to show its main characteristics. The last paragraph is devoted to the summarization and discussion of the results, as well as to the proposal of a research agenda on the subject.

\section{Literature review}

Tourism has always been described as an information intensive domain (Gretzel, Yu-Lan \& Fesenmaier, 2000; Buhalis, 2000) where information processing and gathering is essential (Sheldon, 1997) for day to day operations. Furthermore the recent advances of new technologies radically reshaped the tourism industry (Buhalis, 2003) changing both the way of communicating with prospective tourists and the way of purchasing tourism goods (Werthner \& Klein, 1999). On one side, tourists are more and more using new media for communication purposes, satisfying their information needs during all stages of consumption of tourism goods (i.e. before - during - after - Gretzel, Fesenmaier \& O'Leary, 2006); on the other side tourism managers are understanding that, if properly managed, new technologies can generate a tremendous added value for their organizations.

Additionally, recent technological developments as well as the spread of the internet are having a notable impact on the education process, transforming educational curricula, learning materials and instructional practices (Sigala, 2002). The tourism and hospitality industry has been described as an industry with one of 
the highest levels of skill shortages and staff turnover (HEFCE, 1998). Moreover, Boisevert (2000) has identified training as a critical success factor for the hospitality industry, a factor, which is considered to be expensive and time consuming. Despite all above-mentioned aspects, quite poor attention has been paid to the role that new technologies already play, and can play in the future, in the tourism learning sphere.

According to Haven and Botterill (2003), eLearning involves the delivery and administration of learning opportunities and support via computer, networked and web-based technology, to help individual performance and development. The advantages, challenges and opportunities of eLearning have been exploited as well as widely mentioned, e.g. flexibility in terms of time and place of delivery, continuous professional development, catalyst for institutional transformation (Poehlein, 1996), while its relevance and advantages for tourism and hospitality education has been acknowledged in the recent years (Christou \& Sigala, 2000; Kasavana, 1999). Sigala (2002) indicates, that the Internet in general and eLearning in particular offer great flexibility to match specific conditions of work within the tourism and hospitality sector. Moreover, Cho \& Schmelzer (2000), believe that eLearning prepares students of tourism \& hospitality programs to think critically, solve problems and make straight decisions, while being technologically competent.

Several attempts to understand and represent the use of eLearning in hospitality and tourism have been made. Braun and Hollick (2006) discussed how flexibly delivered online skills and knowledge sharing could help capacity building in the 
tourism industry. Haven and Botterill (2003) reviewed the existing and potential exploitation of virtual learning environments within hospitality, leisure, sport and tourism. Sigala (2001) reviewed and evaluated the evolution of practices in internet pedagogy in order to identify effective eLearning models for tourism and hospitality education.

Finally the literature in the eLearning community has also been investigated, but no research has been found here on the tourism subject; for instance, the database of articles and papers managed by the Association for the Advancement of Computers in Education (AACE), which lists 20,303 items, does not list any relevant article/paper in the tourism field (AACE, 2009).

Up to now, a map of existing online courses in hospitality and tourism has not yet become available, nor a consistent categorization of them was made. This article proposes a tentative map of current online training programs in hospitality and tourism, a categorization of them and an understanding of their main common characteristics. At the same time, many related issues are identified and proposed for further investigations.

\section{Research design and methodology}

Purpose of this study:

Based on the literature review, the absence of an extensive research on eLearning in hospitality and tourism field has been identified, as well as the lack of a map of online training courses, as a result, the general purpose of this study is to map and classify, according to formal criteria of knowledge map classification (Eppler, 
2008), existing online courses in the field of hospitality and tourism, in order to understand their main characteristics, settings, intended users as well as the key aims of creating those courses by providers of the educational services.

Thus, the main research objectives are:

(i) to identify the presence of online training courses in the hospitality and tourism domain;

(ii) to group existing online trainings depending on their similarities, and

(iii) to identify the main characteristics of each group.

\section{Methodology:}

In order to tackle these objectives, as well as to estimate the various types of existing online training programs in the hospitality and tourism industry, a multiple case study research approach was used. The multiple case study research method was considered to be suitable for the study, which involves an in-depth evaluation of novel educational solutions within a real life context.

In order to select a representative sample for the research, an opportunistic model has been used. Information (i.e. the web addresses of the courses) was collected by the researchers within the first three result pages of two popular web search engines: google.com and yahoo.com (ComScore, 2008). Altogether, 300 unique results were collected and analyzed in order to tackle the research objectives. Both search engines were queried in the period from 9th to 13th of March 2009, from Lugano (Switzerland). 
Selection of keywords:

In order to create a map of existing online training courses, a set of specific keywords was identified based on the keyword selection method for characterizing text document maps (Lagus and Kasaki, 1999) to be used to query the two most popular web search engines, namely Google and Yahoo! The keywords set corresponds to the general users' image of online training courses in the hospitality and tourism industry.

The keywords were divided into three sub-categories with the main aim to generate a clear map of all existing online training courses in the hospitality and tourism industry:

1. keywords in the first subcategory indicate that training happens totally or partially online: "eLearning", "Online", "Distance" and "Blended learning";

2. keywords in the second subcategory represent the setting in which the learning/teaching experience is taking place: "Course", "Training", "Program", "School”, “College”, “Institute”, “University", "Corporate Education”;

3. the third subcategory shows that the topic of the course is devoted to the tourism and hospitality industry: "Travel", "Tourism", "Hospitality", "Catering" (Restaurant, Fast Food), "Accommodation" (Hotel/Chain, B\&B), "Transportation" (Cruise, Airline, Railway, Car rental), "Travel agent”, "Tour Operator”.

[INSERT FIGURE 1] 
The keywords from each subcategory were blended and used to perform the search activities. The first three result pages (30 results, with the normal search engine setting of 10 results per page) were taken into consideration and regarded as appropriate for the study, as they are considered relevant for end-users both from academia and from industry (iProspect, 2006). Removing duplicates and non relevant results, keywords combinations were entered in the the search engines until 300 unique results were gathered. Finally, a matrix was created in order to be used as an instrument for the analysis of present online trainings courses and programs.

\section{$\underline{\text { Results }}$}

Many different classification criteria have been tried - such as, for instance, the topic of the course, its level, the technologies being used or its intended audiences - but none of them was able to provide a convincing map, being either not mutually exclusive (e.g.: different audiences for the same course, or more than one technology used) or not collectively exhaustive, or - finally - ill-defined (e.g.: course level, and sometimes also course topic).

The only criterion that proved to be well-defined, offering at the same time the characteristics of being mutually exclusive and collectively exhaustive (i.e.: able to capture all 300 results) was based on the course provider. Four different providers' categories have been modeled: Academic, Corporate, Destination Management Organization and Independent.

Hereafter, a detailed definition of them can be found. 
(i) Academic: refers to all online training courses whose provider is an officially registered academic/educational establishment. This category comprises courses such as Tourism and Travel Management associate diploma at Chemeketa Community College ( ${ }^{*}$ The links of the online courses mentioned in the article can be found after the Reference section), or Hospitality and Tourism Management degree program at Sheffield Hallam University, or Diploma in Tourism Management at Nelson Marlborough Institute of Technology.

(ii) Corporate: online trainings, whose provider is a company or an institution working in the tourism field, and manages online training for its own employees as well as for travel agents who sell its products. Examples are: Académie Accor North America Corporate Training, Royal Caribbean Cruise Lines Corporate University, or Hilton University.

(iii) Destination Management Organization: refers to the courses offered by Destination Management Organizations (national, regional or local) to travel agents and travel operators, who sell the country (region, city, etc.) as a tourist destination. E.g.: South Africa tourism expert course, or Switzerland Travel Academy. 
(iv) Independent: associates with all the courses, whose provider is a third party, neither an academic institution, nor a tourism enterprise, nor a destination management organization. Nevertheless, the topic of the course lie within the tourism and hospitality industry. E.g.: Gourmet Cooking and Catering Program, Certificate course in Ecotourism/Food and Beverage Management.

\section{Exploring the four areas of the map}

A frequency descriptive analysis has been used in order to understand the presence of each category among the selected 300 online training courses. 116 results (39\%) out of 300 results in total belong to the Independent category, while 114 (38\%) correspond to Academic; 39 courses (13\%) belong to Corporate, and 31 $(10 \%)$ are courses organized by Destination Management Organizations.

[INSERT FIGURE 2]

In the following lines, each group is presented, and sub-groups indentified.

\section{$\underline{\text { Academic }}$}

As mentioned above, Academic online courses are those training programs, whose provider is an officially registered academic/educational establishment. Within the academic online courses (114 out of 300 ), 5 subcategories were identified. These were (i) Master (14\%), (ii) Bachelor (28\%) and (iii) Associate (29\%) programs, with 
the possibility for the user to get an officially recognized diploma upon successful fulfillment of them. In addition, there were (iv) a range of separate courses (11\%) and (v) single courses (18\%), in both cases these are not part of an academic diploma program, but still give the possibility for a user to get an officially registered certificate or a transcript.

[INSERT GRAPH 1]

Academic online trainings offer a wide range of topics: Hotel and Restaurant Administration (ex. Institute of Applied Science and Technology - SIAST), Mobility Management (ex. Open University Business School), several courses on computer reservations systems (ex. Hayton College; Canadian Tourism College), Casino management (UMassOnline), etc. The main target of academic courses are young people, who would like to receive interactive educational materials as well as to engage with tutors in a way that still leaves the possibility for the students to look for a part-time employment, enabling a certain flexibility in terms of time and place of where receiving academic instructions. A second target group consists of tourism employees, who are looking for long-life learning opportunities, in order to enhance and deepen their professional skills with a theoretical background.

\section{$\underline{\text { Corporate }}$}

In this group are listed all the courses, whose main provider is a company or an institution, which works in the tourism field, and manages online training for its 
employees and/or for travel agents, who sell its tourist products. Among the overall result of 39 corporate courses, 14 are for internal training, created to train the employees of a company, while 25 serve as specialized external training platforms for travel agents.

As for the company-provider, there is a slight difference in their distribution. In corporate internal training the majority - 8 companies (58\%) out of 14 are airline companies, followed by fast food enterprises; while in corporate external trainings the majority - 9 companies (36\%) out of 25 - lie within the cruising industry, followed by hotel establishments with 6 training courses (24\%).

It would be crucial to mention that many corporate training platforms, as well as trainings offered to partners and sellers may be hosted in intranets, hence not reachable by search engines' "crawlers", which index the web pages. While all three other categories are aimed to external publics (i.e. Academic, Destination Management Organizations, Independent), and interested in being found by prospective users/clients; the corporate trainings does not need to attract external people, as they have already pre-defined audience: employees of the tourism and hospitality enterprises..

In fact, no activity is likely to be done by a company to get a better search engine ranking for its employees' training activities. In many cases pages devoted to the employees' trainings are excluded by search engine "crawlers", as a result search engines are not allowed to include them in their indexes and users outside of the company are not able to participate in the course. 
To further map this category, both in terms of eLearning penetration in the industry and in terms of different providers using it for which publics, a survey seems to be more adequate, as it will allow to get profound insights of the courses.

\section{Destination Management Organization}

This category refers to the training courses created by Destination Management Organizations on 3 levels: national (representation of a country), regional (administrative and geographical part of the country), and local (capital, city or even a smaller tourist destination).

The geographical distribution is rather equal: national training courses such as the Mauritius Tourism Training course or the South Africa tourism expert course comprise $45 \%$ of the total number (14 courses out of 31 ), regional courses, such as the Scotland Tourist Board Training or South Pacific Specialist online training for travel agents account for 29\% (9 courses) and local courses, such as Abu Dhabi Tourism Champions or Puerto Vallarta e-learning Campus generate 26\% (8 courses).

The main target are travel agents, who with the help of such a training should be able to better communicate and sell the country as a tourist destination, improving the service and knowledge level they can offer to their customers. The main topics presented in these courses cover the following issues: factual information about the country (history, geography, political organization, culture, languages, etc.), presentation of the main attractions, formalities (health issues, visa, custom), information on accommodation, catering, entertainment, etc. 


\section{$\underline{\text { Independent }}$}

The next category is associated with all the courses, whose provider is a third party, not an academic institution, not a tourism enterprise, neither a destination management organization, but still the main topic of the course stays within tourism and hospitality industry.

There is no one clearly identified target in this category, as the courses could be used by all the users interested in the industry: from schoolboys in order to check their geography knowledge, to university students in order to pass a test and get a certificate in English Language in Tourism and Hospitality, to adults who are eager to challenge themselves and get a certificate in Amadeus Online Training or pass a Culinary Tourism Course, to senior people who are interested in travel writing.

While a wide variety of topics are covered in this area, 11 main sub-categories can be identified:

- Introduction into hospitality industry

- Tourism management

- Sales and retail activities

- Catering

- Foreign languages (mainly English) in tourism

- Independent travel agent trainings

- Eco tourism or sustainable tourism development

- e-skills development

- Cabin crew training 
- Travel writing

- (Others)

In the following graph, the sub-categories are shown according to their presence in the analyzed sample:

[INSERT GRAPH 2]

\section{Conclusions and Limitations}

This research has assessed the presence of eLearning courses in the hospitality and tourism fields, classifying existing online courses according to their providers, yielding to four different groups: Academic, Corporate, Destination Management Organization and Independent. Each group has also been qualitatively further described according to its relevant audiences and training topics.

This research has used a blended qualitative-quantitative methodology to tackle the research goals presented above, collecting cases in order to design an overall map of the explored territory.

To follow up, the four areas could be further articulated. Due to the set of keywords used, online courses aimed at practitioners have been privileged, but many others are around aiming at improving and enriching tourists' own experience (e.g. offering a better understanding of modern art, or insights into artistic movements). This remark is closely connected with the distinction between formal and non- 
formal or informal training, where neither curricula nor proper courses/modules are offered, but a large variety of learning experiences, very often not explicitly labeled as "teaching" or "learning".

In this article, only "courses" (or "curricula" or "modules") have been taken into consideration, in fact, with the spreading of so called web2.0 (O'Reilly, 2005) informal education and knowledge sharing are getting more and more important, so that blogs, podcasts, wikis, social networks have started to play an important role in life-long learning, up-skilling and knowledge gathering within the travel and tourism community. Future research efforts should include also those learning tools and strategies.

Further explorations could be devoted to two main tracks: different research strategies could be adopted in order to provide maps with finer granularity. Particularly, the Corporate area should be approached through surveys, to assess eLearning penetration (Cantoni \& Succi, 2008), and taught topics, while Destination Management Organizations could be analyzed one by one - at least at the national level - to provide a comprehensive picture of their online offers. The same can be said about the Academic area, where universities and schools can be studied one by one in given areas.

Future research might also deal with a double dimension analysis in all the four areas: each area can be investigated vertically, understanding learners, type of content, strategies and so on; whilst, the investigation could be also horizontal, in order to take into consideration all the providers and technologies used by them in order to train specific learners. 
Results of this study are of interest for both the academic and the professional communities involved in Tourism and eLearning.

To the academic community, the study offers a first map of online courses in Tourism and Hospitality, showing at the same time the relevance of the researched field and promising future research directions.

For the professional community, results provide a clear picture of an important market, whose development can yield to an higher professionalization of the industry and - as a consequence - to a better service being offered to all tourists. 


\section{Figures and Tables}

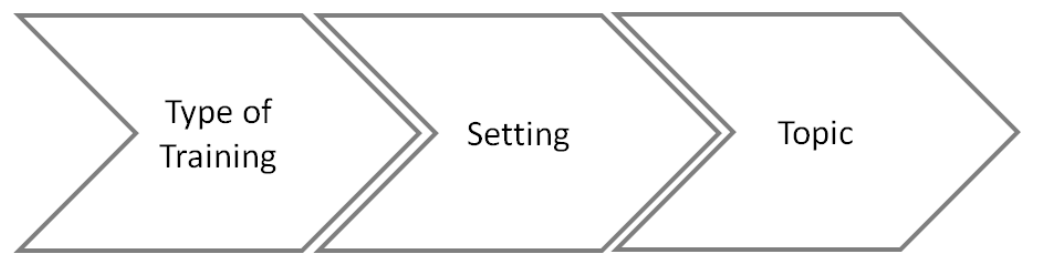

[Figure 1. Keywords selection schema]

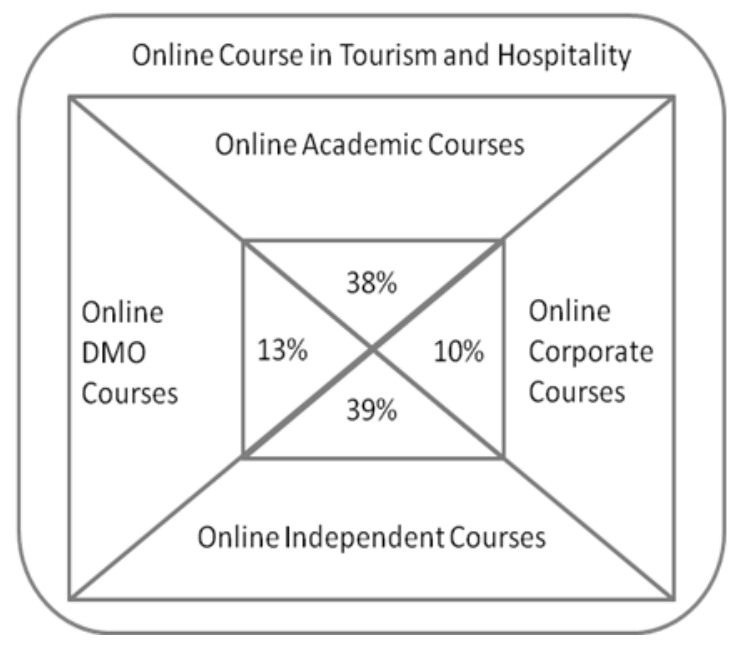

[Figure 2. Classification of online course in the tourism domain]

\section{Graph 1. Types of academic courses}

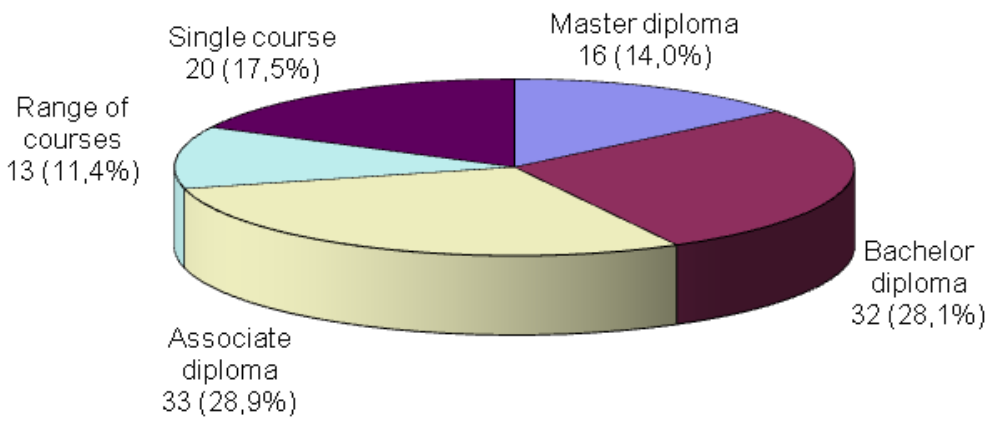




\section{Graph 2. Independent Trainings. Subcategories}

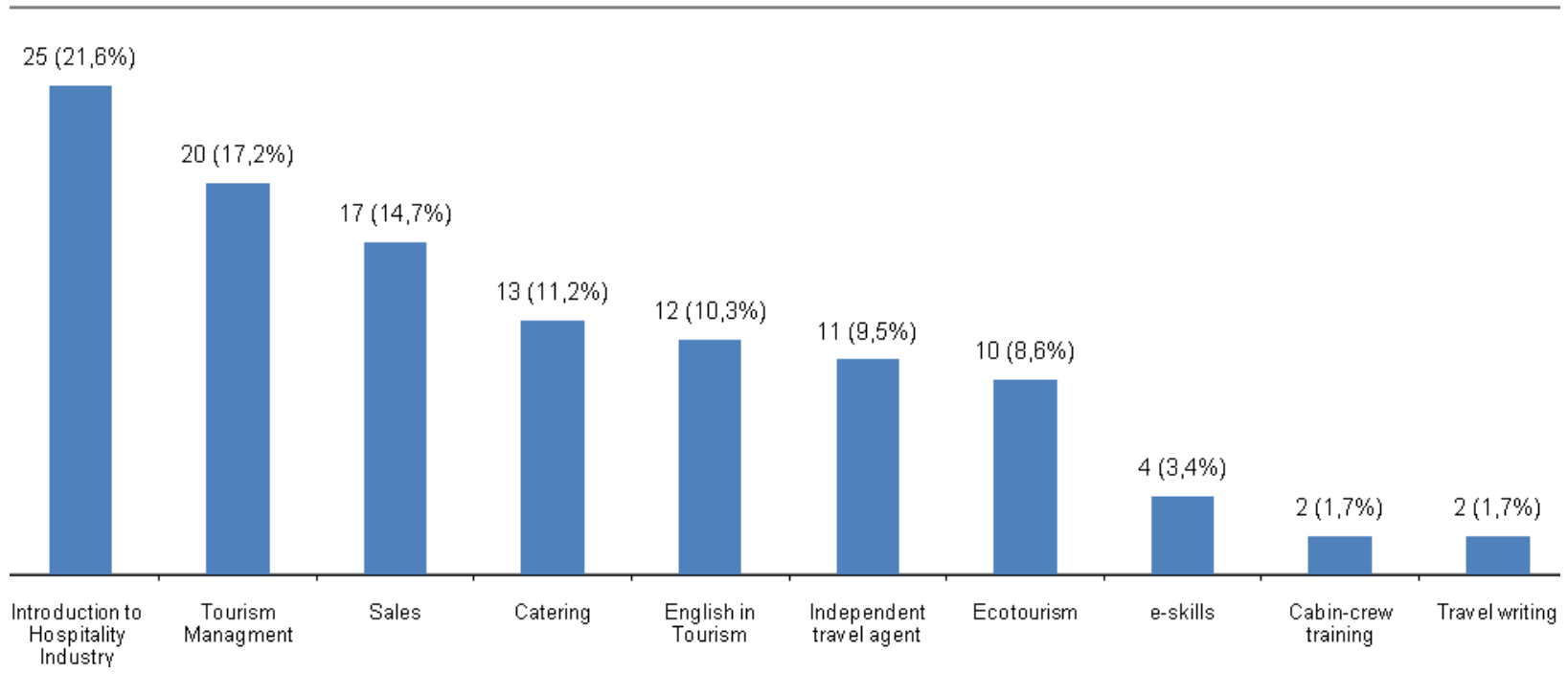




\section{References}

AACE. (2009, January). Association for the Advancement of Computing in Education. Retrieved from: http://www.editlib.org/

Boisevert, L. (2000). Web-based learning, the anytime, anywhere classroom. Information Systems Management, 17 (1), 35-40.

Braun, P., \& Hollick, M. (2006). Tourism skills delivery: Sharing tourism knowledge online. Education+Training, 48 (8/9), 693 - 703.

Buhalis, D. (2000). Marketing the competitive destination of the future, Tourism Management, 21 (1), 97-116.

Buhalis, D. (2003). eTourism: Information technology for strategic tourism management. Prentice Hall: Harlow.

Buhalis, D., \& Spada, A. (2000). Destination Management Systems: Criteria for success. Information Technology and Tourism, 3 (1), 41-58.

Cantoni, L., Botturi, L., Succi, C., \& New MinE Lab. (2007). E-learning. Capire, progettare, comunicar. Milano: Franco Angeli.

Cantoni, L., \& Rega, I. (2003). eLearning studies looking for fixed stars: a study on referenced literature in SITE 2001. In L. Cantoni \& P. Schulz (Eds.), Studies in Communication Sciences. Special Issue 'New Media in Education', 23-37. USI: Lugano.

Cantoni, L., \& Succi, C. (2008). A Map of eLearning Acceptance (MeLA) and a Corporate eLearning Readiness Index (CeLeRI). iJAC - International Journal of Advanced Corporate Learning, Volume 1, Issue 1, 39-47.

Cantoni, L., \& Tardini, S. (2006). Internet. Routledge: London-New York.

CEC. (2001). Communication from the Commision to the Council and the European Parliament, The eLearning Action Plan: Designing Tomorrow's Education. COM: Brussels.

Cho, W., \& Schmelzer, C.D. (2000). Just-in-time education: tools for hospitality managers of the future? International Journal of Contemporary Hospitality Management, 12 (1), 31-37. 
Christou, E., \& Sigala, M. (2000). Exploiting Multimedia for Effective Hospitality Education. EuroCHRIE Spring Conference Proceedings. Dublin: Dublin Institute of Technology.

ComScore. (2008, March). comScore Releases December U.S. Search Engine Rankings. Retrieved from

http://www.comscore.com/press/release.asp?press=2016

Eppler, M. (2008). A process-based classification of knowledge maps and application examples. Knowledge \& Process Management, 59-72.

Gretzel, U., Fesenmaier, D.R., \& O'Leary, J.T. (2006). The transformation of consumer behavior. In D. Buhalis, C. Costa (Eds.), Tourism Business Frontiers, (918). Elsevier: a Butterworth-Heinemann.

Gretzel, U., Yu-Lan, Y., \& Fesenmaier, D. (2000). Preparing for the New Economy: Advertising Strategies and Change in Destination Marketing Organizations. Journal of Travel Research, 39(2), 146-156.

Haven, C., \& Botterill, D. (2003). Virtual Learning Environments in Hospitality, Leisure, Tourism and Sport: A Review. Journal of Hospitality, Leisure, Sports and Tourism Education, 2 (1), 75-92.

HEFCE. (1998). Review of Hospitality Management. London: HEFCE.

iProspect. (2006, April). iProspect. Retrieved from http://www.iprospect.com

Kasavana, M. (1999). Educating and empowering through web-based technology. Lodging, 59-60.

Lagus, K., Kasaki, S. (1999). Keyword selection method for characterizing text document maps. Ninth International Conference on Artificial Neutral Networks Proceedings (ICANN'99). London: IEE Press, 371-376

O'Reilly, T. (2005, September). What Is Web 2.0. Retrieved from http://www.oreillynet.com/pub/a/oreilly/tim/news/2005/09/30/what-is-web-20.html

Poehlein, G. (1996). Universities and information technologies for instructional programmes: issues and potential impacts. Technology Analysis and Strategic Management, 8 (3), 283-290. 
Sheldon, P. (1997). Tourism Information Technology. CAB: Oxford.

Sigala, M. (2001). Re-engineering Tourism Education Through Internet: From Virtual Classes to Virtual Communities. Tourism Society Conference in Tourism Education. Guildford: University of Surrey.

Sigala, M. (2002). The Evolution of Internet Pedagogy: Benefits for Tourism and Hospitality Education. Journal of Hospitality, Leisure, Sport and Tourism Education, 29-45.

Werthner H., \& Klein S. (1999). Information Technology and Tourism - A Challenging Relationship. Wien-New York: Springer Verlag. 


\section{WebLinks to online courses:}

Académie Accor North America Corporate Training www.elementk.com/documentView.asp?docid=9

Canadian Tourism College - www.tourismcollege.com

Certificate course in Ecotourism/Food and Beverage Management www.acseduonline.com/courses/

Diploma in Tourism Management at Nelson Marlborough Institute of Technology http://ecampus.nmit.ac.nz/moodle/course/category.php?id=150

Gourmet Cooking and Catering Program - www.pcdi.ca/courses/2f/

Hayton College - www.hayton.com.au

Hilton University - http://lms.hilton.com/landingpage/index.html

Hospitality and Tourism Management degree program at Sheffield Hallam University - www.rdi.co.uk/distance-learning/hospitality-tourism-degree.html

Institute of Applied Science and Technology (SIAST) -

http://programs.siast.sk.ca/vc/cont ed programs courses/

Open University Business School - www.open.ac.uk/

Royal Caribbean Cruise Lines Corporate University - www.remotelearner.net/node/102

South Africa tourism expert course - http://www.safundi.net/

Switzerland Travel Academy - http://elearning-st.myswitzerland.com/

Tourism and Travel Management associate diploma at Chemeketa Community College -

http://learning.chemeketa.edu/course descriptions/catalog/34/default.htm

UMassOnline - www.umassonline.net/degrees/Online-Degree-BachelorHospitality-Tourism-Management.cfm 